\title{
Otite equina por Proteus mirabilis - relato de caso
}

Paula Alessandra Di Filippo', Gabriel Carvalho Santos, Veronica Vieira, Gabriela Bravim Lemos, Italo dos Santos Coutinho, Flávio Augusto Soares Graça

*Autor correspondente

e-mail: paula_difilippo@yahoo.com.br

\section{Resumo}

A otite, definida como a inflamação das estruturas auditivas, é classificada de acordo com a região anatômica acometida. A otite interna envolve o nervo vestíbulo-coclear e pode ser causada por bactérias, vírus ou fungos, infestação parasitária, neoplasias, lesões vasculares e disfunção imune. 0 animal acometido frequentemente apresenta sintomas vestibulares periféricos, como desvio e rotação da cabeça e paralisia do nervo facial ipsilateral. Os sinais neurológicos advêm da diminuição da drenagem pelos condutos auditivos em razão do edema de mucosa e obstrução por exsudato, que podem ocasionar infecções persistentes e lesão dos nervos faciais. A otite externa é uma afecção do epitélio do conduto auditivo, podendo também acometer o pavilhão auricular. 0 diagnóstico etiológico da otite primária em equinos é de difícil realização, devido ao canal auditivo externo ser longo e à dificuldade de visualização da membrana timpânica. Entretanto, quando realizado, o diagnóstio favorece a instituição precoce e específica do tratamento e, consequentemente, a cura do animal. 0 objetivo desde estudo foi descrever o quadro clínico de um equino diagnosticado com otite por Proteus mirabilis. 0 equino macho, 18 anos de idade e $320 \mathrm{~kg} / \mathrm{pv}$, foi atendido no Hospital Veterinário da Universidade Estadual Norte Fluminense (HVET-UENF) -RJ com histórico de apatia, perda do equilíbrio resultando em quedas frequentes, dificuldades em se alimentar, sonolência e inchaço na base da orelha esquerda. Segundo relato do proprietário, há 40 dias o animal havia se envolvido em uma briga com um outro animal e nesta ocasião, havia lesionado a orelha. Ao exame físico, o animal apresentava comprometimento do nervo facial, clinicamente notado pela paralisia facial unilateral do lábio superior e inferior. Após avaliação clínica, procedeu-se o exame otológico detalhado. No interior do conduto auditivo, notou-se a presença de exsudato abundante e fétido. 0 animal sentia dor à palpação externa do conduto auditivo. A colheita do material foi realizada introduzindo-se um swab estéril o mais profundamente possível no canal auditivo vertical. Após este procedimento, foi feita também a colheita de exsudato e/ou cerúmen 
para a confecção de esfregaços e posterior observação microscópica. 0 material colhido foi semeado em ágar Sabouraud dextrosado (Sabouraud Dextrose 2\% Agar) acrescido de cloranfenicol e azeite de oliva estéril. Os meios de cultura foram deixados em incubação por até 28 dias à temperatura ambiente após inoculação. As colônias crescidas no meio de cultura foram identificadas como Proteus mirabilis. Baseado no antibiograma, instituiu-se tratamento com gentamicina $(6,6 \mathrm{mg} / \mathrm{kg}$, IV, SID, 4 dias), penicilina benzatina $(20.000 \mathrm{UI} / \mathrm{kg}$, IM, SID, 7 dias), flunixin meglumine $(0,5 \mathrm{mg} / \mathrm{kg}$, IV, SID, 3 dias $)$ e curativo local com clorexidinedergemante e pomada à base de neomicina (BID/7 dias). 0 tratamento instituído resultou na cura completa da afecção e dos sintomas. 0 sucesso na resolução deste caso deu-se, principalmente, à precisão no diagnóstico, o qual permitiu a instituição do tratamento adequado, que colaborou, ainda, para a manutenção anatômica normal do pavilhão auricular acometido.

Palavras-chave: Antibiograma. Inflamação auricular. Cavalo. 